\title{
Studi Pengaruh Pemasangan NGR 40 Ohm pada Uprating Transformator 2 GI Gianyar Terhadap Gangguan Hubung Singkat 1 Phasa Tanah
}

\author{
I.K.A.S.Darma ${ }^{1}$,I.G.D.Arjana ${ }^{2}$,A.A.G.M.Pemayun ${ }^{3}$
}

\begin{abstract}
Along with the development of ever-increasing burden on the GI Gianyar then the transformer unit 2 with a capacity of $30 \mathrm{MVA}$ will be uprating with a capacity of $60 \mathrm{MVA}$ transformer. To maintain the continuity and reliability of the flow of electrical power to the consumer, NGR (Neutral Grounding Resistance) and relay $S B E F$ is used as the safety equipment of the short circuit 1 phase to ground was not in to the neutral point of the transformer. Uprating of transformers that have been done changes on 1 phase fault current to ground when using a direct earthing systems with a value to become 1838.21 A. While the value of the short-circuit current 1 phase to ground after pairing NGR 40 Ohm value is fixed at $288.675 \mathrm{~A}$, so that the current setting and time relay SBEF fixed at $90 A$ and 7.067 seconds. The analysis result from the effect of installation NGR and rele SBEF on the transformer 60 MVA against short circuit 1 phase to ground has the ability good protection for the value of the fault current is able to be reduced from 1838,21 A into 288.675 A after pairing NGR 40 Ohm and time is needed SBEF to handle distractions 7.067 seconds.
\end{abstract}

Intisari- Seiring dengan perkembangan beban yang terus meningkat di GI Gianyar maka transformator unit 2 berkapasitas 30 MVA akan di lakukan uprating (penggantian) dengan transformator berkapasitas 60 MVA. Untuk menjaga kontinyuitas dan keandalan aliran daya listrik sampai ke konsumen (beban), NGR (Neutral Grounding Resistance) dan rele SBEF dipergunakan sebagai peralatan pengaman dari gangguan hubung singkat phasa tanah agar arus gangguan 1 phasa ke tanah tidak sampai mengalir ke titik netral transformator. Dari uprating transformator yang sudah di lakukan terjadi perubahan pada arus gangguan 1 phasa ke tanah jika menggunakan sistem pentanahan langsung (solid grounding) menjadi 1838,21 A. Sedangkan nilai dari arus hubung singkat 1 phasa ke tanah setelah dipasangkan NGR $40 \mathrm{Ohm}$ nilainya tetap sebesar 288,675 A, sehingga setting arus dan waktu rele SBEF tetap sebesar 90 A dan 7,067 detik. Hasil analisis pengaruh pemasangan NGR dan rele SBEF pada transformator $60 \mathrm{MVA}$ terhadap gangguan hubung singkat 1 phasa ke tanah menghasilkan kemampuan proteksi yang lebih baik karena nilai arus gangguan yang mampu di kurangi dari 1838,21 A menjadi 288,675 A setelah dipasangkan NGR $40 \mathrm{Ohm}$ dan waktu yang di butuhkan SBEF untuk menangani gangguan 7,067 detik.

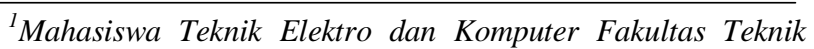
Universitas Udayana, Kampus Bukit Jimbaran, Badung Bali. 80361, Tel. 0361703315 fax. 0361703315; email :arya_suryadharma30@yahoo.com

${ }^{2,3}$ Dosen Teknik Elektro dan Komputer Fakultas Teknik Universitas Udayana, Kampus Bukit Jimbaran, Badung Bali. 80361, Tel.0361703315 fax.0361703315; email :dyanaarjana@unud.ac.id
Kata kunci : NGR 40 Ohm, Rele SBEF,GI Gianyar, Uprating.

\section{PENDAHULUAN}

Jaringan sistem transmisi dan jaringan sistem distribusi memiliki peranan penting dalam hal penyaluran daya listrik, dari pembangkit hingga tersalurkan kepada konsumen (beban). Namun dalam proses penyaluran, terkadang timbul berbagai gangguan yang dapat menghambat kinerja sistem tenaga listrik. Untuk menjaga kontinyuitas dan keandalan sistem tenaga listrik dalam proses penyaluran daya listrik tersebut, maka dibutuhkan berbagai sistem proteksi (pengaman) dari gangguan yang mungkin timbul seperti gangguan hubung singkat phasa ke tanah, jaringan distribusi primer $20 \mathrm{kV}$ yang berada pada transformator 2 GI Gianyar sebelum di uprating yang berkapasitas 30 MVA menggunakan sistem proteksi untuk gangguan hubung singkat satu phasa tanah dengan rele GFR (Ground Fault Relay) pada sisi incoming,penyulang dan metode pentanahan titik netral menggunakan tahanan dan di dampingi rele SBEF (Stand by Earth Fault).

Berdasarkan data yang di himpun dari PT PLN di gardu induk Gianyar dan hasil penelitian yang sudah di lakukan sebelumnya [1]. Transformator unit 2 GI Gianyar awalnya memiliki kapasitas sebesar 30 MVA ,mempergunakan sistem proteksi GFR dan sistem pentanahan dengan metode pemasangan tahanan NGR di dampingi rele SBEF,namun hasil evaluasi dari PT. PLN pada GI Gianyar menunjukkan kegagalan proteksi pada pengaman gangguan hubung singkat satu phasa tanah sehingga terjadi trip pada transformator secara menyeluruh,hal ini menyebabkan metode pentanahan diganti menjadi pentanahan langsung (solid grounding) ,namun kembali dari hasil evaluasi menunjukkan metode pentanahan langsung ,menimbulkan arus gangguan yang cukup besar sehingga di perkirakan ketika adanya arus gangguan yang besar dan mengalir kembali masuk ke dalam transformator dapat membahayakan rangkaian phasa transformator itu sendiri, hal ini menunjukkan indikasi terjadinya kesalahan pada penentuan besaran tahanan dan koordinasi sistem proteksi hubung singkat satu phasa tanah, pada saat transformator akan di uprating menjadi berkapasitas 60 MVA sistem pentanahan kembali akan menggunakan metode pemasangan tahanan NGR $40 \mathrm{Ohm}$ sebagai proteksi utama yang berfungsi sebagai pengaman akibat gangguan hubung singkat phasa - tanah,penggantian kapasitas transformator secara langsung akan mempengaruhi besarnya arus gangguan hubung singkat yang mungkin di timbulkan. 
Berdasarkan teori dan fakta di lapangan tersebut diperlukan solusi untuk mendapatkan pilihan yang baik bagi sistem pentanahan dan rangkaian sistem pengaman transformator terhadap gangguan hubung singkat satu phasa ke tanah. Solusinya adalah dengan melakukan penelitian terhadap kemampuan tahanan yang akan di pasang dan kemungkinan adanya kesalahan koordinasi sistem proteksi pada rele GFR sisi penyulang,sisi incoming sebagai proteksi awal gangguan hubung singkat satu phasa ke tanah dan rele SBEF sebagai proteksi tahanan NGR. Dalam penelitian ini akan dilakukan perhitungan kekuatan tahanan NGR $40 \mathrm{Ohm}$ dan perhitungan setting pengaman rele GFR,rele SBEF .

\section{SISTEM PENTANAHAN DAN RELE PENGAMAN}

\section{A. Sistem Pentanahan}

Sistem pentanahan atau grounding system merupakan sistem pengaman perangkat yang mempergunakan listrik sebagai sumber tenaga utama, terhadap lonjakan arus listrik yang bersumber dari alam seperti utamanya petir atau dari kerusakan alat itu sendiri [2]. Sistem pentanahan yang di pergunakan pada transformator 2 GI Gianyar merupakan sistem pentanahan titik netral transformator yang pada prinsipnya merupakan dasar yang di gunakan untuk suatu sistem proteksi.

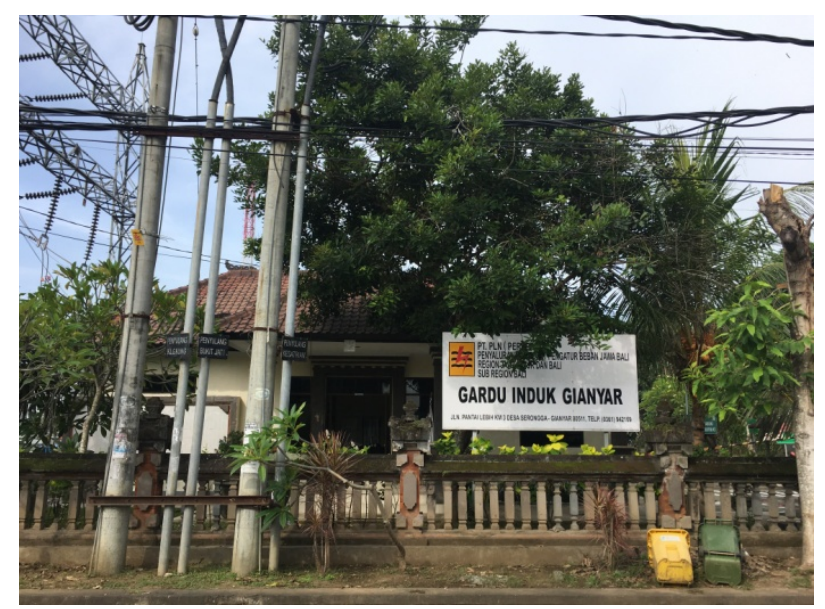

Gambar 1:Gardu Induk Gianyar

\section{B. Tujuan Sistem Pentanahan}

1. Membatasi besar tegangan terhadap bumi agar berada dalam batasan yang diperbolehkan Menyediakan jalur bagi aliran arus listrik yang dapat memberikan deteksi terjadinya hubungan yang tidak dikehendaki antara konduktor system dan bumi. Deteksi ini akan mengakibatkan beroperasinya peralatan otomatis yang memutuskan suplai tegangan dari konduktor tersebut [3]

\section{Jenis-Jenis Pentanahan}

1. Sistem pentanahan langsung (Solid Grounding)

Sistem pentanahan menggunakan metode ini,adalah dimana titik netral transformator di tanahkan/dibumikan secara langsung melalui kawat tanah.
2. Sistem pentanahan dengan tahanan

Sistem pentanahan menggunakan metode ini,adalah dimana titik netral transformator tidak di tanahkan/dibumikan secara langsung,melainkan kawat tanah di hubungkan secara seri ke tahanan yang bernilai tertentu terlebih dahulu sebelum dihubungkan ke tanah.

Beberapa besaran tahanan yang di pakai oleh PT. PLN adalah sebagai berikut [4] :
a. NGR $12 \mathrm{Ohm}$
b. NGR $40 \mathrm{Ohm}$
c. NGR $500 \mathrm{Ohm}$.

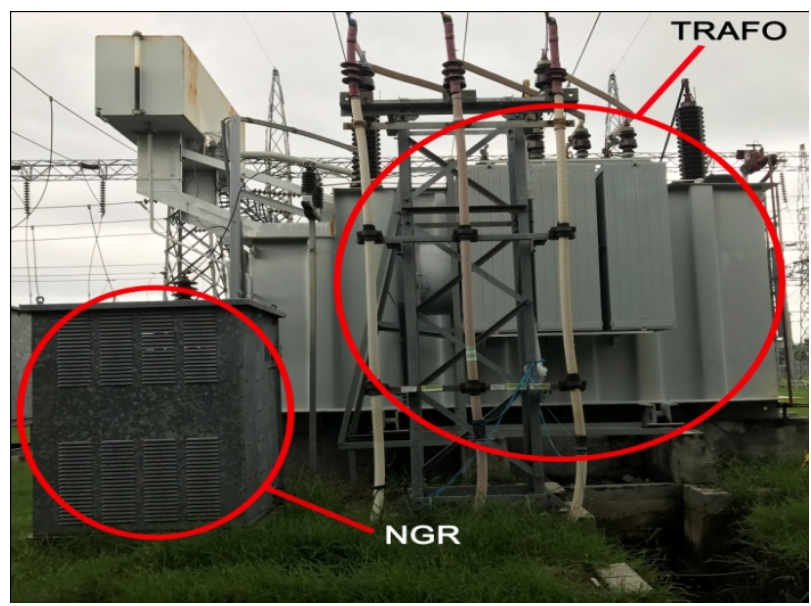

Gambar 2:Transformator 2 dengan NGR GI Gianyar

\section{Gangguan Hubung Singkat Satu Phasa ke Tanah}

Gangguan hubung singkat merupakan gangguan yang terjadi karena adanya kesalahan atau kegagalan kerja antara bagian-bagian yang bertegangan. Gangguan hubung singkat dapat memunculkan arus yang jauh lebih besar dari pada arus normal dan dapat menimbulkan kerusakan peraltan jaringan dan mengganggu batas-batas kestabilan sistem daya [5] Gangguan hubung singkat satu phasa ke tanah juga disebut gangguan tidak simetris yaitu terjadi hubung singkat pada salah satu phasa ke tanah.

\section{E. Bagian-bagian dan Prinsip Kerja Rele}

Prinsip kerja rele pada umumnya dapat dibedakan menjadi tiga elemen fundamental [6].

1. CT (Sensing Elemen), rasio transformator atau trafo arus mengukur perubahan besaran listrik, misalnya perubahan arus atau tegangan pada sistem.

2. Rele digital (Comparing Elemen), komponen rele bertugas membandingkan besaran yang terukur dengan besaran yang telah diset sebelumnya.

3. PMT (Control Elemen), Pemutus tenaga merupakan komponen yang menerima sinyal atau mengontrol rangkaian lain, misalnya membuat sakelar suatu rangkaian tertutup.

\section{F. Rele Arus Lebih (Over Current rele)}

Rele arus lebih adalah rele yang bekerja hanya berdasarkan adanya kenaikan arus yang melebihi suatu nilai 
pengaman tertentu [7] yang melewatinya.Selain mengamankan peralatan terhadap naiknya arus, rele pengaman ini harus juga dapat bekerja pada jangka waktu yang telah ditentukan sehingga pengaturan waktu dapat dikaitkan dengan masalah koordinasi pengaman.

\section{G. Prinsip Dasar Perhitungan Gangguan Arus Hubung Singkat}

Gangguan hubung singkat yang mungkin terjadi pada jaringan sistem tenaga listrik ada 3 :

1. Gangguan hubung singkat 3 phasa

2. Gangguan hubung singkat antar phasa atau 2 phasa

3. Gangguan hubung singkat 1 phasa ke tanah

Dari semua gangguan hubung singkat di atas, arus gangguannya dihitung dengan menggunakan persamaan berikut [2] [8]:

1. Gangguan hubung singkat 1 phasa ke tanah

a. Dengan NGR

$\mathrm{I}_{1 \varnothing 20}=\frac{\mathrm{V}_{\mathrm{S}} \cdot 1000}{\sqrt{3} \cdot \mathrm{NGR}}$

b.Tanpa NGR

Impedansi dasar

$Z d=\frac{K V_{\text {dasar }}^{2}}{M V A_{\text {dasar }}} \Omega$

Reaktansi transformator

$\mathrm{Xt}=\mathrm{Z}_{\mathrm{T}} \mathrm{x} \mathrm{Ztr}$

Arus dasar

$I \quad$ dasar $=\frac{K V A_{3} \phi \text { dasar }}{\sqrt{3} * \text { tegangan dasar }\left(K V_{L L}\right)}$

Impedansi sumber

$Z_{S}=\frac{K V^{2} \text { dasar }}{M V A h s} \Omega$

Arus hubung singkat 1 phasa ke tanah

$I h s=\frac{V(3 * \text { tegangan phasa netral })}{Z(\text { impedansi total })}=A$

Keterangan:

$\mathrm{I}_{1 \varnothing(20)} \quad$ : Arus hubung singkat satu ke tanah fasa di sisi $20 \mathrm{kV}$

$\mathrm{I}_{\mathrm{hs}} \quad$ : Arus hubung singkat

$\mathrm{V}_{\mathrm{p}} \quad$ : Tegangan sisi primer

$\mathrm{V}_{\mathrm{s}} \quad$ : Tegangan sisi sekunder

$\mathrm{Z}_{\mathrm{tr}} \quad:$ Impedansi trafo

$\mathrm{Zd} \quad$ : Impedansi dasar trafo

Zs : Impedansi Sumber

H. Prinsip dasar perhitungan setting hubung tanah (GFR)
Rele hubung tanah yang di kenal dengan GFR (Ground Fault Relay) bekerja untuk mendeteksi adanya hubung singkat ke tanah. Untuk setting arus GFR pada sisi primer dan sekunder trafo tenaga terlebih dahulu harus di hitung arus nominal transformator tenaga. Arus setting untuk rele GFR baik pada sisi primer maupun pada sisi sekunder transformator tenaga [9]:

Iset $($ prim $)=0,2 \times$ Inom

Nilai tersebut adalah nilai primer, untuk mendapatkan nilai setting pada sekunder yang dapat di setting pada rele GFR, maka harus di hitung dengan menggunakan rasio trafo arus (CT) yang terpasang pada sisi sekunder di transformator tenaga. Berikut persamaan dari setting arus pada rele GFR [1] :

$\operatorname{Igfr}=\frac{0,2 \cdot \text { Inom }}{\text { CT }}$

Keterangan :

$$
\begin{array}{ll}
\text { Igfr } & =\text { Arus pada rele } \\
\text { Inom } & =\text { Arus nominal pada transformator } \\
\text { CT } & =\text { Rasio transformator }
\end{array}
$$

\section{Prinsip dasar perhitungan penyetelan waktu}

Penyetelan arus pada rele arus lebih umumnya didasarkan pada penyetelan batas minimumnya, dengan demikian adanya gangguan hubung singkat dibeberapa seksi berikutnya, rele arusnya akan bekerja. Untuk mendapatkan pengamanan yang selektif, maka penyetelan waktunya dibuat secara bertingkat.

Syarat untuk men setting waktu ( $\mathrm{Td} /$ Time dial atau TMS/Time multiple setting) dari rele arus lebih dengan karakteristik waktu terbalik, harus diketahui terlebih data Besarnya arus hubung singkat pada setiap seksi,data Penyetelan/setting arusnya (Iset),dan data Kurva karakteristik rele yang dipakai.

Untuk persamaan yang dapat di gunakan untuk menghitung Td (time dial) atau TMS (Time multiple setting) adalah [10]:

$T_{d}=\frac{\left(\frac{I 1 f 20}{I_{s p}}\right)^{0.02}-1}{0,14} . S I$

Keterangan:

\begin{tabular}{ll} 
Td & $:$ Time delay \\
Isp & : Arus hubung singkat 1 phasa \\
0,02 & $:$ Standard kemanan karakteristik invers \\
0,14 & $:$ Standard kemanan peralatan rele \\
SI & $:$ waktu yang di inginkan untuk rele bekerja \\
& \\
& III. METODE PENELITIAN \\
\multicolumn{1}{c}{ Penelitian } & ini dilaksanakan di PT PLN (Persero)
\end{tabular}
Penyaluran dan Pusat Pengatur Beban Jawa Bali, Area Pelaksana Pemeliharaan (P3B JB APP) Bali Gardu Induk Gianyar. Penelitian ini dilaksanakan dari bulan Mei 2015. Adapun alur langkah penelitian ini dilakukan dalam beberapa tahapan diantaranya : 
1. Pengumpulan data transformator terpasang di GI Gianyar,data single line diagram,data setting rele,dan data setting ngr dari data base ruang kontrol Gi Gianyar.

2. Menghitung arus hubung singkat yang terdapat di bus 20 $\mathrm{kV}$.

3. Menganalisa koordinasi setting rele dari hasil perhitungan arus hubung singkat di bus $20 \mathrm{kV}$.

4. Memodelkan hasil perhitungan dengan mathcad guna memunculkan grafik koordinasi pada masing-masing rele.

\section{HASIL DAN PEMBAHASAN}

A. Hasil Perhitungan Setting Pengaman Transformator 2 GI

\section{Gianyar}

Hasil perhitungan setting pengaman Transformator unit 2 GI Gianyar, pada GFR penyulang, GFR sisi Incoming, NGR, dan rele SBEF menggunakan persamaan 1 sampai 9 untuk menghasilkan nilai setting arus dan setting waktu di transformator 2 berkapasitas 30 MVA sebelum di uprating dan transformator 2 berkapasitas 60 MVA setelah di uprating. Berikut adalah hasil perhitungan arus dan waktu GFR penyulang ,GFR sisi Incoming,NGR dan rele SBEF di transformator $60 \mathrm{MVA}$ dengan data name plate trafo sebagai Perhitungan arus dan waktu pada GFR penyulang

a. Setting arus GFR pada penyulang

$$
\begin{aligned}
& \operatorname{Ig}_{\text {peny }} \quad=\frac{0,2 \cdot I_{\text {peny }}}{\mathrm{CT}_{\text {peny }}} \\
& \text { dipilih } \quad \operatorname{Ig}_{\text {peny }}=0,625 \mathrm{~A}
\end{aligned}
$$

b. Setting waktu GFR pada penyulang

Waktu yang dikehendaki: 0,9detik

$$
\begin{aligned}
\mathrm{T}_{\mathrm{d}} & =\frac{\left(\frac{\mathrm{T}_{\mathrm{NGR}}}{\text { Ipgeny }}\right)^{0,02}-1}{0,14} \cdot 0,9 \quad=\frac{\left(\frac{40 \mathrm{sec}}{50}\right)^{0,02-1}}{0,14} \cdot 0,9 \\
& =0,255 \mathrm{SI} \text { dipilih } \mathrm{T}_{\mathrm{d}}=0,25 \mathrm{SI}
\end{aligned}
$$

Waktu actual :

$$
\begin{aligned}
\operatorname{Tg}_{\text {penyact }}= & \frac{0,14}{\left(\frac{t_{\text {NGR }}}{\text { Ipgpeny }^{0}}\right)^{0,02}-1} \cdot \mathrm{T}_{\mathrm{d}} \\
& \frac{0,14}{\left(\frac{40}{50}\right)^{0,02}-1} \cdot 0,25=0,981 \text { detik }
\end{aligned}
$$

1. Perhitungan arus dan waktu pada GFR sisi Incoming

a. Setting Arus GFR pada sisi incoming $20 \mathrm{kV}$

Sekunder

$\mathrm{I}_{\mathrm{ssg}}=\frac{0,2 \cdot \mathrm{I} 1 \mathrm{f} 20}{\mathrm{CT}_{\mathrm{s}}}$

$=\frac{0,2 \cdot 288,675}{2000 / 5}=0,144 \mathrm{~A}$

dipilih $=0.15 \mathrm{~A}$

b. Setting Waktu GFR pada sisi incoming $20 \mathrm{Kv}$

Waktu kerja relay sisi incoming : 2 detik

$T_{d}=\frac{\left(\frac{I 1 f 20}{I_{s p}}\right)^{0.02}-1}{0,14} \cdot 2=\frac{\left(\frac{288,675}{280}\right)^{0.02}-1}{0,14} \cdot 2=0,456 \mathrm{SI}$

Waktu aktual

I Kadek Arya Surya : Studi Pengaruh Pemasangan NGR...

$$
\begin{aligned}
T_{a c t} & =\frac{0,14}{\left(\frac{I 1 f 20}{I s p 1}\right)^{0.02}-1} \cdot T_{d}=\frac{0,14}{\left(\frac{288,675}{140}\right)^{0.02}-1} \cdot 0,475 \\
& =2.083 \text { detik }
\end{aligned}
$$

2. Perhitungan arus hubung sinkgat satu phasa tanah sebelum di pasangkan NGR

a. Nilai arus hubung singkat satu phasa tanah sebelum di pasang NGR

$$
I h s=\frac{3 * 20.000 / \sqrt{3}}{2 * 6,8447+(6,84474+36)}=1838,21 \mathrm{~A}
$$

b. Nilai arus hubung singkat satu phasa tanah setelah di pasangkan NGR

$$
\text { Ingr }: \mathrm{I}_{1 \varnothing 20}=\frac{\mathrm{V}_{\mathrm{S}} .1000}{\sqrt{3} \cdot \mathrm{NGR}}=\frac{20.1000}{\sqrt{3} \cdot 40}=288,675 \mathrm{~A}
$$

3. Perhitungan arus dan waktu pada rele SBEF

a. Setting Arus SBEF pada proteksi NGR

$$
\begin{aligned}
& \begin{array}{l}
\mathrm{I}_{\text {sbef }}=0,3 . \text { Ingr } \\
\text { dipilih }
\end{array} \\
& \begin{array}{l}
0,3.288,675 \mathrm{~A}=86,603 \\
\text { Isbef }=90 \mathrm{~A}
\end{array}
\end{aligned}
$$

b. Setting waktu SBEF pada proteksi NGR

Waktu yang di kehendaki untuk trip tsbef $=7$ detik

$$
\begin{aligned}
& \text { tsbef1 }=\frac{\left(\frac{I n g r}{I_{n s}}\right)-1}{120} \cdot \text { tsbef }=\frac{\left(\frac{288,675}{90}\right)-1}{120} \cdot 7=0,129 \\
& \text { dipilih }=0,13 \mathrm{LT}
\end{aligned}
$$

Waktu actual :

$$
\text { tsbef5 } 1=\frac{120}{\left(\frac{\text { Ingr }}{\text { Isbef }}\right)-1} \cdot \text { tsbef } 1=\frac{120}{\left(\frac{288,675}{90}\right)-1} \cdot 0,13=7,067 \mathrm{detik}
$$

\section{B. Hasil perhitungan arus hubung singkat 1 phasa ke} tanah.

Berikut adalah hasil perhitungan arus dan waktu di sisi penyulang pada pengaman GFR di transformator 230 MVA yang belum di uprating dan transformator 260 MVA yang sudah di uprating.

TABEL I

$$
\text { HASIL PERHITUNGAN GFR PADA PENYULANG }
$$

\begin{tabular}{|c|c|c|c|}
\hline \multirow{2}{*}{ No } & \multirow{2}{*}{ Perhitungan } & \multicolumn{2}{|c|}{ Transformator } \\
\cline { 3 - 4 } & & $30 \mathrm{MVA}$ & $60 \mathrm{MVA}$ \\
\hline 1 & Issg & $0,3 \mathrm{~A}$ & $0,15 \mathrm{~A}$ \\
\hline 2 & Td2 & $0,46 \mathrm{SI}$ & $0,475 \mathrm{SI}$ \\
\hline 3 & Tact & 2,18 & 2,083 detik \\
\hline
\end{tabular}

Berikut adalah hasil perhitungan arus dan waktu di incoming $20 \mathrm{kV}$ pada pengaman GFR di transformator 30 MVA yang belum di uprating dan transformator 60 MVA yang sudah di uprating

TABEL II 
HASIL PERHITUNGAN GFR PADA INCOMING $20 \mathrm{KV}$

\begin{tabular}{|c|c|c|c|}
\hline \multirow{2}{*}{ No } & \multirow{2}{*}{ Keterangan } & \multicolumn{2}{|c|}{ Transformator } \\
\cline { 3 - 4 } & & $30 \mathrm{MVA}$ & $60 \mathrm{MVA}$ \\
\hline 1 & Igpeny & O,625 A & $0,625 \mathrm{~A}$ \\
\hline 2 & Td3 & $0,25 \mathrm{SI}$ & $0,2 \mathrm{SI}$ \\
\hline 3 & Tact & 0,98 detik & 0,37 detik \\
\hline
\end{tabular}

Berikut adalah hasil perhitungan setting nilai NGR sebagai proteksi terhadap gangguan hubung singkat satu phasa ke tanah di transformator 30 MVA yang belum di uprating, dan transformator 60 MVA yang sudah di uprating :

TABEL III

HASIL PERHITUNGAN DARI SETTING NILAI NGR

\begin{tabular}{|c|c|c|c|}
\hline \multirow{2}{*}{ No } & \multirow{2}{*}{ Perhitungan } & \multicolumn{2}{|c|}{ Transformator } \\
\cline { 3 - 4 } 1 & $\begin{array}{c}\text { Sebelum di } \\
\text { pasangkan NGR }\end{array}$ & 30 MVA & 60 MVA \\
\hline 2 & $\begin{array}{c}\text { Sesudah di } \\
\text { pasangkan NGR }\end{array}$ & $288,675 \mathrm{~A}$ & $1838,21 \mathrm{~A}$ \\
\hline
\end{tabular}

Berikut adalah hasil perhitungan arus dan waktu pada pengaman Rele SBEF di transformator 230 MVA yang belum di uprating dan transformator 260 MVA yang sudah di uprating:

TABEL IV

HASIL PERHITUNGAN SBEF

\begin{tabular}{|c|c|c|c|}
\hline \multirow{2}{*}{ No } & \multirow{2}{*}{ Perhitungan } & \multicolumn{2}{|c|}{ Transformator } \\
\cline { 3 - 4 } & & $30 \mathrm{MVA}$ & $60 \mathrm{MVA}$ \\
\hline 1 & Isbef & $90 \mathrm{~A}$ & $90 \mathrm{~A}$ \\
\hline 2 & tsbef1 & $0,13 \mathrm{LT}$ & $0,13 \mathrm{LT}$ \\
\hline 3 & tact & 7,067 detik & 7,067 detik \\
\hline
\end{tabular}

C. Grafik koordinasi setting rele GFR penyulang,GFR incoming $20 \mathrm{kV}$,dan rele SBEF transformator $60 \mathrm{MVA}$

Dari hasil perhitungan pengaman GFR penyulang,GFR incoming dan SBEF di transformator $60 \mathrm{MVA}$ di peroleh tampilan grafik dengan menggunakan program mathcad untuk mengetahui bahwa pada masing-masing zona yang di amankan oleh pengaman GFR dan SBEF berfungsi secara baik secara koordinatif. Berikut adalah grafik dari koordinasi setting rele pada penyulang $20 \mathrm{kV}$, incoming $20 \mathrm{kV}$,dan netral sekunder transformator. Hasil pemodelan grafik bisa di lihat bahwa tidak terdapat persilangan antar garis menunjukkan bahwa koordinasi kerja antar rele berfungsi dengan baik.

\section{KESIMPULAN}

Berdasarkan perhitungan pada pembahasan dan analisis setting pengaman pada transformator 2 GI Gianyar, dapat di simpulkan bahwa pengaruh pemasangan NGR 40 Ohm pada uprating transformator 2 GI Gianyar, menunjukkan bahwa pemasangan NGR $40 \mathrm{Ohm}$ mampu menahan arus gangguan hubung singkat satu phasa tanah dengan baik.
Koordinasi G51 Penyulang dan SBEF

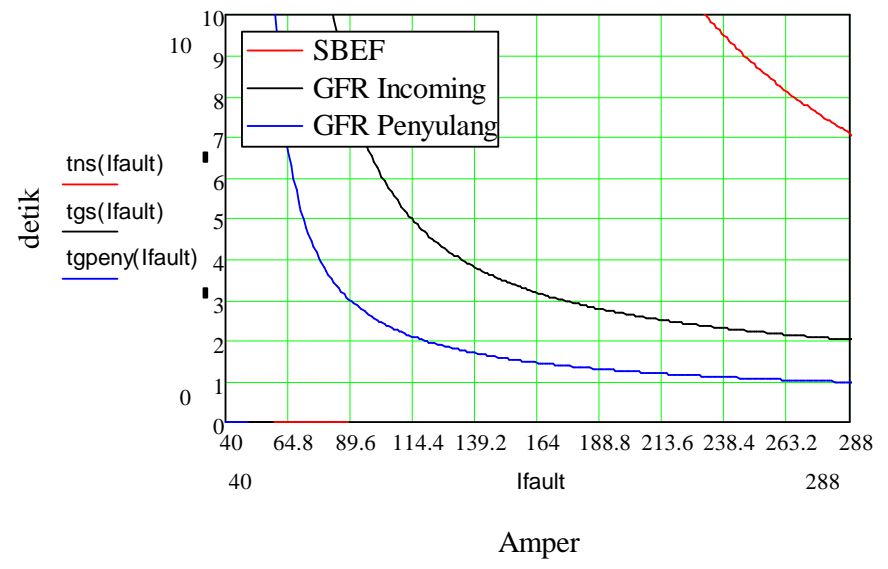

Gambar 3: Hasil grafik koordinasi setting rele GFR penyulang,GFR incoming,dan SBEF

Hal ini di tunjukkan dari hasil perhitungan pada pembahasan dimana, arus gangguan hubung singkat satu phasa ke tanah adalah sebesar 1362,57 A pada trafo berkapasitas 30 MVA dan 1838,21 A pada trafo berkapasitas 60 MVA, peningkatan arus gangguan ini disebabkan oleh perbedaan besar nilai impedansi (Z) akibat di tingkatkannya kapasitas pada transformator tersebut,dan setelah di pasangkan NGR 40 Ohm,bahwa hasil perhitungan dari arus gangguan hubung singkat satu phasa ke tanah yang di dapat adalah sebesar 288,675 A, hal ini disebabkan oleh besarnya tahanan 40 Ohm yang di miliki NGR.

Hasil analisis dari perhitungan setting rele SBEF di transformator 30 MVA yang di uprating menjadi 60 MVA menghasilkan nilai setting arus yang sama sebesar 90 A dan membutuhkan waktu yang sama sebesar 7,067 detik untuk mengamankan titik netral trafo dari gangguan arus hubung singkat satu phasa ke tanah, kesamaan ini disebabkan oleh besar nilai NGR yang di pasang yaitu $40 \mathrm{Ohm}$.

Hasil grafik transformator 230 MVA sebelum di uprating dan 60 MVA setelah di uprating mempunyai koordinasi setting pengaman yang baik karena tidak terdapat persilangan antar pengaman penyulang,pengaman sisi incoming,dan pengaman pada sisi netral sekunder transformator berjalan sempurna.

Setting arus dan waktu rele GFR penyulang,incoming dan rele SBEF Transformator 2 GI Gianyar disarankan untuk dilakukan pemeriksaan kembali sesuai dengan hasil perhitungan.

\section{REFERENSI}

[1] P.G Eko Putra. 2015. Analisis koordinasi Setting Relay Pengaman Akibat Uprating Transformator di Gardu Induk Gianyar. Denpasar: Jurusan Teknik Elektro Fakultas Teknik Universitas Udayana.

[2] I.G.B Nyoman Suryana. 2003. Studi Penggunaan Relay Restricted Earth Fault (REF) Pada Sistem Pengaman Transformator - 4 150/20 KV di Gardu Induk Kapal. Denpasar:Jurusan Teknik Elektro Fakultas Teknik Universitas Udayana.

[3] IEEE Standards Association. 242.,2001.Recommended Practice for Protection and Coordination of Industrial and Commercial Power 
System. New York: The Institue of Electrical and Electronics Engineer, Inc.

[4] Kelompok Disain Enjinering Konstruksi Jaringan Distribusi Tenaga Listrik dan Pusat Penelitian Sains dan Teknologi Universitas Indonesia. 2010. Buku 1 Kriteria Disain Enjinering Konstruksi Jaringan Distribusi Tenaga Listrik. Jakarta: PT PLN (PERSERO).

[5] Indra Baskara, "Studi Koordinasi Peralatan Proteksi OCR dan GFR Pada Penyulang Tibubeneng,'Majalah Ilmiah Teknologi Elektro, Vol. 14 No.2, Juli-Desember 2015.

[6] Titarenko, and Dukelsky, N. 1977.Protective Relaying in Electrical Power System. Moscow: Peace Publisher.

[7] Zulkarnaini, E, Saputra, H., 2008. Evaluasi Koordinasi Relay Proteksi pada feeder Distribusi tenaga listrik (GH Tanjung Ampalu Sijunjung). Padang: Program Studi Teknik Elektro Fakultas Teknologi Industri Teknologi Padang

[8] I Made Mataram, "Profil Sistem Kelistrikan Bali Pasca GI Pemecutan Kelod Dan PLTU 780 MW Celukan Bawang Beroperasi,"Majalah Ilmiah Teknologi Elektro, Vol. 9 No.1, Januari-Juni 2010

[9] Irfan Affandi. 2009. Analisa Setting Rele Arus Lebih Dan Rele Gangguan Tanah Pada Penyulang Sadewa di Gi Cawang. Depok: Program Studi Teknik Elektro Fakultas Teknik Universitas Indonesia.

[10] I K Anom Astana Ady. 2016. Studi Pengaruh Setting Rele Pengaman Untuk Meminimalkan Gangguan Sympathetic Trip Pada Penyulang Bunisari - Suwung. "Majalah Ilmiah Teknik Elektro,Vol. 15. No.2,JuliDesember 2016. 